LANDMARKS AND FUTURE PROSPECTS IN LINGUISTICS: AN ARGUMENT FOR THE STUDY OF SIGNATURE IN TEXT

\title{
PERCURSOS E PERSPECTIVAS EM LINGUÍSTICA: UM ARGUMENTO A FAVOR DO CONCEITO DE ASSINATURA VALORATIVA
}

\author{
Anna Elizabeth Balocco*
}

\begin{abstract}
Linguistics has contributed to the study of the social, discursive and institutional factors that affect language use (with the concepts of genre and register), but it must continue to push this investigation in the direction of studies of singularity in language. In this paper, this argument takes the form of a discussion of the concept of "signature" within Appraisal Theory (MARTIN \& WHITE, 2005). To put forward such an argument, a corpus of published book reviews is discussed.
\end{abstract}

KEYWORDS: systemic functional linguistics; appraisal; style; signature

RESUMO: A linguística tem se ocupado dos fatores sociais, discursivos e institucionais que afetam o uso da linguagem (através dos conceitos de gênero e registro), mas deve avançar na direção dos estudos da singularidade na linguagem. Neste artigo, este argumento assume a forma de uma discussão do conceito de "signature" da Teoria da Valoração (MARTIN \& WHITE, 2005), um quadro teórico para o estudo da avaliação na linguagem. Para apresentar este argumento, discute-se um corpus de resenhas literárias publicadas em jornal.

PALAVRAS-CHAVE: linguística sistêmico-funcional; valoração; estilo; assinatura valorativa

\footnotetext{
"Rio de Janeiro State University (UERJ), $\mathrm{PhD}$ in Linguistics (UFRJ), Associate Professor, annabalocco@terra.com.br
} 


\section{INTRODUCTION}

One of systemic-functional linguistics' main tenets is that language and context are interdependent; much the same kind of interdependence exists between systemic-functional linguistics (hereafter SFL) and linguistics, seeing that SFL is part of the context of research in the area of language studies. SFL's fate is thus inextricably linked to that of linguistics.

This being said, the article discusses landmarks and future prospects in the area of SFL, in the understanding that the reflexivity between theoretical framework and intellectual context will give weight to the limited perspective adopted in this article.

The paper's main aim is to argue that SFL has contributed a great deal to exploring the dialectical relationship between the linguistic system and language use (with the concepts of genre and register, for example), but it must continue to push forward the investigation of the social, discursive and institutional factors that affect language use in the direction of studies of singularity in language, or of the relationship between system and individual, tackling what in SFL is called the principle of individuation. In this paper, this argument takes the form of a discussion of the concept of "signature" within Appraisal Theory (MARTIN \& WHITE, 2005), a framework for the study of evaluation in language, from a systemic-functional perspective. 
To put forward an argument for the importance of focus on the dimension of singularity in SFL, in particular, and in language studies at large, a corpus of ten published texts in the area of literature, written by a well known journalist, is discussed, with a view to deepening our understanding of the relationship between value systems coded in the semantic potential of a language and the construction of a specific evaluative signature in text.

\section{STARTING POINTS}

The interdependence between language and context has been widely acknowledged in most theoretical quarters in language studies, to the point of becoming a dogmatic assumption in functional linguistics, and in systemic functional linguistics, in particular. What changes from one theoretical framework to another is the way this relationship is treated, or conceptualized.

In SFL, the dialectical relationship between language and context has been conceptualized in paradigmatic terms, which has given a particular format to the theory, organized around three different principles: realization; instantiation; and individuation (MARTIN, 2008a).

The first principle refers to a scale of abstraction in linguistic systems, whereby one dimension of meaning is re-codified (or re-interpreted) at a higher level of abstraction. For example, in the process of meaning production, the phonological system is re-codified as lexicogrammar, and this dimension of meaning is further interpreted as discourse semantics, a higher level of abstraction as it encompasses phenomena pertaining to the level of the textual and discursive organization of language.

The second principle, that of instantiation, relates the linguistic system to its contexts of use. It is thus thought of, not as a scale of abstraction relating distinct levels of meaning, but as a scale of generalization, going from the semantic potential of a language (the system) down to an instance of use, in a particular social situation (MARTIN, 2008a: 32). The parameters focussed on when one is dealing with the principle of instantiation are register and genre, which enable researchers to explore the social, discursive, and institutional factors that have a bearing on language use.

Finally, the third principle. According to Martin (2008a:30), individuation is the principle that enables investigation of the relationship between the linguistic system and the way it is deployed by a particular individual. This is a "less developed" domain in SFL, the author continues, which thus merits further exploration. To date, it seems that only research done on "coding 
orientation" by Hasan (1996) and on "signature" by Martin himself (2008a) have dealt with this principle.

The principle of individuation relates culture to individual. For a better understanding of the nature of this relationship, Martin draws on the metaphors of "reservoir" and "repertoire" proposed by Bernstein (1996 In: MARTIN, 2008b: 35): individuation explores the relationship between the meaning potential of a language (its "reservoir" of meanings) and the "repertoire" of meanings articulated, in text, by a single individual.

The relationship between reservoir and repertoire of meanings allows for investigation and theoretical speculation about the category of 'subject', which has recently received a great deal of attention in language studies. The speaking subject, in anglophone theory, is not only the subject in a particular context of situation (the immediate context where language takes place), but it is also the subject in a context of culture. This double localization of the subject theoretically aligns SFL with critical realism, a philosophical and intellectual framework characterized by a concern with the study of language and ideology. Within critical realism, one is concerned with norms, conventions, and social values, and how individuals are ideologically affected by such socio-cultural variables. However, critical realism does not neglect the investigation of how individuals are differentially affected by ideology, given their distinct life experiences and social position.

Bringing these notions home to the context of this research, book reviews are governed by discursive and generic restrictions: there are norms in the culture and within journalistic discourse that constrain the production of a book review. However, as a socio-culturally positioned individual, a journalist writing a book review brings distinct resources to bear on his text, which identify it to his readers and transform it into a singular discursive production.

What justifies interest in theoretical thinking about singularity, apart from the fact that this is a "less developed" dimension of SFL, according to Martin? The author himself argues that our role as language researchers is not only to describe the potentialities of the linguistic system, but also to interpret how this semantic potential is used in specific social situations, by individuals who may either simply actualize it (repeating it, so to say), or who may decide to re-shape it, investing their texts or discourses with their own signature (MARTIN \& WHITE, 2005: 208).

However, the principle of individuation can not be dealt with in isolation from the other two principles operating in SFL (realization and 
instantiation), because, as Bernstein reminds us, although there may be significant differences between the individual repertoires of members of a particular culture, the repertoire of each individual "is made up of a common core" (represented by a language's semantic potential as well as its sub-potentials, in different registers and genres) (MARTIN, 2008b: 35).

It is understood, in this paper, that this formulation acknowledges the risk of interpreting the principle of individuation on the basis of concepts like 'author' or 'style', in their Romantic conceptualization as traces of an individual's personality in text, or as the expression of a subject who is impermeable to culture and social institutions. These concepts must be invested with different theoretical overtones if they are to be still valid in language studies.

\section{THE CONCEPT OF STYLE}

The term 'style' has been understood and conceptualized in distinct ways in language studies across time. According to Possenti (2009: 92), a language researcher who has been insistently concerned with the issue of singularity in language studies, the most common conception of style has a Romantic overtone, which puts emphasis on idiosyncratic aspects of an individual's personality.

Discourse analysis (not to mention psychoanalysis and other fields of investigation) has challenged this conception of an individual who is in control of his or her personal intentions and thus of the process of meaning production. This Romantic conception of the subject and the concern with traces of an individual's personality in text was abandoned, in favor of a concern with the social and institutional factors that allow for the emergence of a particular text (in Foucauldian terms, a concern with the social and historical conditions that allow for the emergence of a set of utterances, or discourse).

Two misleading assumptions are behind the Romantic concept of style. The first one, which has just been mentioned, is the notion of a speaking subject who is "omniscient", or in perfect control of his or her intentions. The second one is an outdated conception of language as a homogeneous and stable entity, "frozen and uniform for all speakers" (POSSENTI, 2009: 92).

These two misleading assumptions lead to two equally unsound propositions: the first one, that an individual's style derives from conscious and strategic choices; and, even more important, the notion that style 
may be understood as 'deviation' from a norm. The concept of style as 'deviation' from a norm is based on the idea that the use of language is governed by strongly prescriptive rules. Such a set of well structured linguistic prescriptions would constitute 'language', in a narrow conception of that object, which does not take account of its heterogeneity.

The conception of style as 'choice', in turn, is based on the idea that there are cognitive and psychological factors which account for choice of form of expression in language. Thus, in stylistics, for example, the term 'choice' refers to the assessment of the distinct possibilities of expression available in the lexicon and in syntax. In discourse stylistics, the scope of choices available to a speaker are considerably broadened, to include choices in rhetorical structure or mode, for example, but the conceptions of the speaking subject and of language in this area of study are also misleading and narrow.

Possenti (2009: 93) argues that the notion of choice does not have to be abandoned, as it is a "constitutive category in language". To the author, choice in language is "a structural necessity", given "the varied resources available [to the speaker]". The author's argument coincides with SFL's main theoretical assumption, namely, that language is paradigmatically organized, making available to the speaking subject different semantic resources for the expression of meaning.

Language choice, within this theoretical framework, should not be seen as the assessment of distinct forms of expression available in the lexicon and syntax, but as a feature characteristic of every process of semiosis, from its dimension of an unconscious process that leads to ways of thinking and looking at the world, down to the dimension of the use of specific linguistic forms that embody these worldviews, and their corresponding forms of alignment with interlocutors. It is unnecessary to say, at this point in our argument, that the process is affected by social and institutional parameters, and is not deliberately conscious.

\section{SIGNATURE: FOR A RENEWED CONCEPT OF THE CATEGORY OF 'AUTHOR'}

Like the concept of style, the term 'author' also has a Romantic overtone, associated with the idea of a conscious subject, completely transparent to him or herself and to others. This Romantic notion has also been challenged by the emergence of discourse analysis, psychoanalysis and so-called structuralist and post-structuralist criticism. By the end of the 
$19^{\text {th }}$ century and beginning of the twentieth century, the Romantic concept of author was seriously questioned: in Anglo-Saxon New Criticism, for example, the study of traces of an author's subjectivity in fictional texts gave way to an investigation of the materiality of the text itself (BROOKS \& WARREN, 1938). In the tradition of French sociology of reading, the relationship between author and fictional text is abandoned and one is concerned with reading as a social practice, culturally and historically situated (MAILLOUX, 1982).

Post-structuralist criticism contributed also to the rejection of an absolute subject, in perfect control of his or her intentions: the sixties and seventies questioned the central role assigned to the author. Barthes (in: SELDEN, 1988: 74), for example, announced "the death of the author" $\nabla$ against the "I speak" characteristic of the Romantic author, one is forced to deal with the autonomy of the fictional text: "it speaks"!

To Possenti (2009: 94), the argument for the death of the author had two immediate consequences: first, to show that this is a historically and socially constructed category, largely dependent on the discursive regime of a particular culture and time. A second consequence was the claim that, in Possenti's terms, "the interpretation of a text should not be equated with attempts at discovering an individual's intentions or project". However, the author goes on, the concept of author should not necessarily be abandoned; rather, it should be "appropriated" from a different theoretical perspective.

This is exactly what is done in SFL through the principle of individuation, whereby one is concerned with traces of singularity in language, without neglecting the cultural and discoursal horizons that impose limits to a speaking subject. From this perspective, focus on singularity does not equate with a focus on authorial intentions, or on strategic choices motivated by a conscious subject. Rather, it has to do with the relationship between reservoir and repertoire of meanings: between language as a semantic potential and its actualization in a specific text, taking account not only of discursive and generic constraints, but also of the distinct ways through which the latter intertwine with signature (MARTIN, 2008b: 35).

Signature is about difference, not uniqueness: it is about the difference that results from textuality itself, as, on the scale that goes from realization to instantiation and to individuation, each and every text refers back, differently, to the semantic potential of a language, and to other texts and voices present in the context of culture. 


\section{SIGNATURE IN A SAMPLE OF CRITICAL TEXTS PUBLISHED IN THE PRESS}

To illustrate the principle of individuation, and explore its analytic potential, this part of the paper introduces an investigation of signature in a set of texts published for over a year (03/01/2009 a 12/12/2009) in Prosa $e$ Verso (a weekly literary supplement published by $O$ Globo). The critical reviews are signed by José Castello, a renowned journalist and writer.

\section{1 - THE CORPUS}

Several criteria were adopted in the constitution of the corpus: the first one was the collection of texts over an extended period of time, which enabled the researcher to investigate the features that make these texts recognizable to the journalist's readers. An attempt was also made to collect only critical reviews of fictional books, which led to the exclusion of texts dealing with collections of essays (as in the critical review published in Dec. $5^{\text {th }}$ ); collections of annotations and aphorisms by Canetti (published in October $17^{\text {th }}$ ); letters by Michelangelo (November, $21^{\text {st }}$, 2009); books classified as "children's literature" or "literature for adolescents" (October $\left.10^{\text {th }}\right)$. The assumption here was that this delimitation would prevent the journalist's signature from being influenced by the nature of the book being reviewed.

Another criterium in the delimitation of the corpus was the exclusion of longer critical reviews, published as the front page of the literary supplement, on the occasion of an acclaimed author's launching of a book (Chico Buarque's Leite Derramado, for example), or of a new edition of a classic work in Brazilian literature (As meninas by Lygia Fagundes Telles). Only critical reviews published on page 4 of Prosa e Verso were felt to be appropriate, given that they have rigorously the same printing space $\left(1^{\text {st }}\right.$ and $2^{\text {nd }}$ columns: 46 lines; $3^{\text {rd }}$ column: 81 lines) and are not affected by the newsworthiness of other critical reviews. Space and newsworthiness were understood to be important parameters in the "control", so to say, of variables affecting the writer's signature.

After these delimitations, the corpus of study had 12 texts, one for each month of the year 2009, as described below: 
TABLE 1: DESCRIPTION OF THE CORPUS

\begin{tabular}{|c|c|c|c|}
\hline $\begin{array}{l}\text { DATE OF } \\
\text { THE TEXT }\end{array}$ & $\begin{array}{l}\text { NUMBER } \\
\text { IN THE } \\
\text { CORPUS }\end{array}$ & TITLE & THEME \\
\hline 03/01/2009 & Text 1 & A chave de Pamuk & O. Pamuk, "O livro negro" \\
\hline $21 / 02 / 2009$ & Text 2 & Manaus não existe & Miltom Hatoum, "A cidade ilhada" \\
\hline 07/03/2009 & Text 3 & Viagem para dentro & $\begin{array}{l}\text { Xavier de Maistre, "Viagem à roda } \\
\text { do meu quarto" }\end{array}$ \\
\hline $18 / 04 / 2009$ & Text 4 & A panela de Mary Ann & $\begin{array}{l}\text { Mary Ann Shaffer, "A sociedade } \\
\text { literária e a torta de casca de } \\
\text { batata" }\end{array}$ \\
\hline $16 / 05 / 2009$ & Text 5 & O menino de Lewis & $\begin{array}{l}\text { C. S. Lewis, "Um experimento na } \\
\text { crítica literária" }\end{array}$ \\
\hline $13 / 06 / 2009$ & Text 6 & A bofetada metafísica & Gustavo Bernardo, "Monte Veritá" \\
\hline 04/07/2009 & Text 7 & Sophie, a encoberta & Sophie Calle, "Histórias reais" \\
\hline 08/08/2009 & Text 8 & A clareza da noite & $\begin{array}{l}\text { Haruki Murakami, "Após o } \\
\text { anoitecer" }\end{array}$ \\
\hline $12 / 09 / 2009$ & Text 9 & O crítico aprendiz & $\begin{array}{l}\text { José Eduardo Agualusa, "A } \\
\text { conjura" }\end{array}$ \\
\hline 03/10/2009 & Text 10 & Hotel Trevisan & $\begin{array}{l}\text { Dalton Trevisan, "Violetas e } \\
\text { pavões" }\end{array}$ \\
\hline $28 / 11 / 2009$ & Text 11 & Jogo perigoso & Flavio Carneiro, "O campeonato" \\
\hline $12 / 12 / 2009$ & Text 12 & Que estranho viver & $\begin{array}{l}\text { Antonio Lobo Antunes, "Que } \\
\text { cavalos são aqueles que fazem } \\
\text { sombra no mar?" }\end{array}$ \\
\hline
\end{tabular}

\section{2 - ANALYTICAL CATEGORIES: AFFECT, ATTRIBUTION AND DEFINITIONAL UTTERANCES}

From the point of view of treatment of the data, a decision was made to draw on analytical categories in Appraisal theory (MARTIN \& WHITE, 2005), a framework for the study of evaluation in language. The decision is justified on the grounds that book reviews are, by their very nature, evaluative texts. From 
the three sub-systems in Appraisal theory, it was decided to concentrate on those considered most relevant to the goals of the present study: Attitude ${ }^{1}$ (with its three sub-systems, Affect, Judgement, and Appreciation) and Engagement (with a focus on resources for projection, under the rubric of Attribution). These categories will be explained in the development of the paper.

After preliminary investigation of the corpus, a decision was made to focus exclusively on utterances which explicitly or implicitly codify Affect (emotional responses to the fictional text being reviewed) in $1^{\text {st }}$ person singular or plural, as in the following examples:

A double feeling haunts me $[=$ the reviewer] every time I read him [= the writer Trevisan]. (Text 10, paragraph 17)

(...) Trevisan writes to remind $\underline{\mathrm{us}}$ (= readers and reviewer) that we are always on the verge [of something happening to us]. (Text 10, paragraph 9).

The decision to narrow down the corpus in this way was based on two assumptions. First, that the massive occurrence of tokens of $1^{\text {st }}$ person pronouns (singular or plural) seems to be an invariant feature of the corpus, which contributes to constructing the reviewer's signature. Second, that focus on Affect would favor investigation of the specific positioning strategy adopted by the journalist, with a view to aligning his readers with a particular conception of reading literature.

However, at this point in the preliminary analysis of the corpus, it was noticed that, apart from being predicated of the speaker, or of speaker and readers, Affect in the corpus is also predicated of third persons, in noun phrases which lexicalize as "the reader", "the critic", as in the following examples:

Sick[ened] of the same kind of illusion, Lobo Antunes' reader feels the pang. What weird book I am reading! What am I supposed to do with these voices, that mingle with each other? How can I distinguish them? (Text 12, parágrafo 8)

(...) reading the first book by a writer, the [literary] critic is forced to exercise, more than ever, the foundations of a reading practice: the capacity to be overwhelmed [by the text] (Text 9, paragraph 3)

\footnotetext{
${ }^{1}$ Capital letters are used in SFL to refer to semantic-functional categories of an abstract nature, given their place in a virtual system, namely, that of language as a semantic potential.
} 
In the examples, the reader or critic is discursively represented in the process of reading, and described as having an emotional response to the text. It was thus decided to widen the analytical scope of the research to include such $3^{\text {rd }}$ person utterances in which Affect is predicated of "the reader" or "the critic".

It was also decided to focus on definitional utterances realized as attributive relational processes ${ }^{2}$, whose referent is "literature", "language", "writing", "words", as in the following example:

Lobo Antunes knows that literature is neither explanatory nor decorative. It doesn't 'illustrate' or 'exemplify'; nor does it 'teach'. Words barely touch the world. (...) (Text 12, paragraph 12)

Such definitional utterances also convey the reviewer's conception of literature ("this is what literature is all about") and contribute to aligning the reader with the book reviewer's system of values with respect to literature.

Finally, a decision was made to include under the analytical scope of the project utterances with Attribution ${ }^{3}$, as in the following example:

I take advantage of an idea by José Saramago - his [= Lobo Antunes'] most conspicuous antagonist: "one writes with everything one has inside, only with what one has inside". (Text 12, paragraph 4)

Focus on these utterances allow us not only to describe the heteroglossic framework of the text, or the voices the journalist brings to bear on his text, but also to explore how the book reviewer interacts with his readers through these voices. In the utterance just introduced, for example, the journalist gives his readers information about a personal relationship holding between Antonio Lobo Antunes (the author under scrutiny) and José Saramago, another well known public figure and renowned Portuguese fiction writer. Rather than appraiser, in this textual fragment, the reviewer

\footnotetext{
${ }^{2}$ In LSF, attributive relational processes establish a relationship between two linguistic expressions ( $\mathrm{X}$ is $\mathrm{Y}$ ), one of them being a Carrier (X), the element which carries an Attribute (Y). Although two linguistic expressions are involved, there is only one referent (the Carrier). (THOMPSON, 1996, p. 86).

${ }^{3}$ Attribution (acategoryin theEngagementsub-system) isrealized throughlexicogrammatical resources of projection, in the form of verbal processes whose participants are a Sayer and a Verbal message.
} 
is seen to adopt his role as journalist, responsible for providing his readers with extra-textual information.

Focus on all three kinds of utterances will allow for claims to be made about the reviewer's signature, on the basis of investigation of the functionality of interpersonal relations in the text.

\section{BONDING IN CRITICAL REVIEWS}

It was decided to introduce, in this paper, one critical review (featuring in Appendix I) to illustrate the instantiation of Appraisal resources in the corpus and the construction of a particular kind of signature for the journalist/reviewer. In this review, entitled "What weird thing it is to live!", published in December 12th, 2009, the journalist reviews Portuguese writer Antonio Lobo Antunes' most recent fiction book, entitled "What horses are those casting shadows on the sea?".

As a first approximation, one notices that there are distinct discoursal dimensions in the text: on the first dimension, the journalist adopts the role of someone who is responsible for giving his reader extra-textual information, as in the following fragment: "Written between 2008 and 2009, his new novel has 334 pages. Which end up being 668, or maybe 1336 - seeing that he makes us go back and forth, go back and forth. We read it, re-read it, and it is never enough." (paragraph 10, lines 6-9)

On another dimension, the reviewer gives his readers an idea of the novel's plot, and of characters in the novel, as in the following textual fragment:

The novel begins (it seems, though nothing is really for sure in his books) in the voice of Beatriz, the daughter who survived two broken marriages. 'What weird thing it is to live, how do you do this, where do you start, in which chapter', she complains, as she rebuilds the story of her dead mother. (paragraph 7 , lines $4-10)$.

Finally, on a third dimension, the reviewer responds to the novel, making comments about it, which intermingle with the plot summary and account of characters in the novel:

Beatriz idealizes books, which should be clear and coherent. Sickened of the same illusion, Lobo Antunes' reader feels the pang. What weird book I am reading! What am I supposed to do with these voices, that mingle with each other? How can I distinguish them? How can I order them? And, however, it is thus, in this whirlwind of words - and not on the neat and dry hilltops of rhetoric - that we live. (paragraph 8) 
There is explicit coding of Affect in this fragment, alongside implicit coding. In "the reader feels the pang", through choice of a mental process ${ }^{4}$, the journalist discursively constructs an emotional response to the book, projecting it onto the reader. The ideational strings "What am I supposed to do with these voices? How can I distinguish them? How can I order them?" do not explicitly codify Affect, but evoke it: the questions imply a sense of disorientation, on the part of the reader, as the journalist shifts from $3^{\text {rd }}$ person, at the beginning of the paragraph ("Lobo Antunes' reader"), to $1^{\text {st }}$ person Affect ("What weird book I am reading!"). The journalist does not simply project emotions onto the reader: he speaks on behalf of the reader.

The instantiation of Affect in the fragment does not illustrate a feature of this text only, but of the entire corpus: in all twelve texts Affect predominates, rather than Judgement, or Appreciation. The first category is used in Appraisal theory to refer to various lexicogrammatical resources used in the expression of emotional responses; Judgement is used to refer to evaluation of behaviour or moral conduct; and, finally, Appreciation to refer to the aesthetic appraisal of phenomena or objects.

The predominance of Affect is a surprising feature of the corpus, given the generic nature of its texts. According to Carvalho (2006: 182), the purpose of book reviews is to give readers an overall idea about a book and to introduce evaluative comments about it. These evaluations are generally lexicogrammatically framed as tokens of Appreciation. Here is one example of Appreciation in a book review: "Budapeste, the third and most elaborate novel in his [Chico Buarque's] career as a fiction writer" (Revista Época, 09/15/2003, In: CARVALHO, 2006: 184).

Another distinctive feature of the corpus relates to the kind of realization of Affect in the texts. Martin argues for three semantic sub-categories of Affect: the first one, "affairs of the heart", refers to more subjective emotions ("I like/hate the book"), whereas the second one, "ecosocial well-being", has to do with emotions relating to an individual's perception of his insertion in a particular social group (negative emotions: anxiety, fear; positive emotions: confidence, trust). The last category covers "emotions concerned with telos (the pursuit of goals)"; examples are: ennui, dissatisfaction (negative emotions); satisfaction, pleasure (positive emotions) (MARTIN,

\footnotetext{
${ }^{4}$ In LSF, a mental process takes place, not in the external world (as "he bought the book", a material process), but in the mind ("the reader feels the pang"). This is a process whose participants are a Senser (in this case, "the reader") and a Phenomenon ("the pang"), or what is perceived.
} 
2000: 150). The sub-categorization proves useful in the investigation of the corpus, as one might imagine that emotional responses to fictional text would fall under the category of "affairs of the heart", which is often the case in Brazilian freshmen students' writing in the area of literature (BALOCCO, 2001:188). But this is not what happens in the corpus at issue.

Instances of Affect in the corpus tend to fall under the second category ("ecosocial well-being"), as in the following fragment, from the critical review under discussion:

...His novels are an enormous bunch of voices. These voices beat us up, again, in What horses are those casting shadows on the sea? (Alfaguara). (paragraph 2, lines 2/4)

In the example, coding of Affect is implicit, as the ideational string evokes an emotional reaction: "beating [someone] up" is a material process, which involves an action in the external world. However, in the fragment, it must be understood metaphorically as a mental process ("we are exhausted and disoriented by reading the book"), given the abstract nature of the participant codified as Actor, or doer of the action ("voices [in the book]"). Thus, readers are understood as Sensers (participants who perceive, know, or feel) in a mental process in which "the voices" are the Phenomenon (a participant which triggers a perception). In the following example, implied Affect is also realized as ecosocial well-being, and is also construed on the basis of ideational strings that imply emotional responses:

Who speaks? Rita, the daughter killed by cancer in youth, or Ana, the one who surrendered to drugs? João, the son who conceals his homosexuality, or the old father himself? Voices and more voices, which get tangled up and, instead of enlightening us, make us deaf. What weird thing it is to hear them. (paragraph 9)

In the example, implicit Affect is evoked by a mental process, in which readers and the book reviewer are construed as Sensers ("voices make us deaf") and "the voices" are the Phenomenon, the participant which triggers loss of hearing, associated with feelings of disorientation and discomfort. The same kind of Affect is to be found in the next sequence:

Every now and then a character wonders: 'Is this you?' The doubt pursues the reader till the last page. As in a long distance call jumbled up in crossed lines, 
we wonder: who speaks, after all? Antonio Lobo Antunes' voice, the man's [voice], mingles with fictional voices and becomes fiction, the voice itself, and the man himself. (paragraph 14)

Once again Affect is codified as "ecosocial well-being": this is a response that is not triggered by an individual and subjective reaction ("I like the book or I don't like it"), but rather by feelings related to the reader's particular manner of relating to the world. In this case, the reader is Senser and "the doubt" is Phenomenon, or what is perceived".

Construing readers' responses to literature on the basis of perceptions of the aesthetic qualities of books is what critics and reviewers do when they tap on our perceptions of proportionality ("a long-winded book") or complexity ("an intricate plot"), for example, to give just two dimensions of Appreciation. But this is not what José Castello is doing here; the journalist is trying to construe readers' emotional responses to literature by inviting them to engage in a particular kind of relationship with literature. One that does not presuppose detachment and appreciation of aesthetic qualities, but rather involvement and a personal relationship to literature.

On the other hand, the book reviewer invites reflections about the nature of literature, and of what it means to read literature. This is suggested by the occurrence of definitional utterances in the corpus:

Lobo Antunes knows that literature is neither explanatory nor decorative. It doesn't 'illustrate' or 'exemplify'; nor does it 'teach'. Words barely touch the world. At one point in What horses are those..., the narrator, Beatriz, very irritated, complains about the author: "Words go too fast and the paper is not enough, here is Antonio Lobo Antunes skipping sentences, not able to follow me and drowning in a tank the small cats of my discomfort to get rid of me". Using words does not mean accounting for [= what is out there in the world]. Language is narrower than experience. (paragraph 12)

The example introduces relational processes, in which the Carrier (the participant which carries an Attribute) is "literature", "using words", or "language". The journalist thus informs his view of the character and of the novel with reflections about the nature of literature, of writing ("using

\footnotetext{
${ }^{5}$ A feature of mental processes is their reversibility: the grammatical role of subject may be filled by either a human participant (a Senser) or by a Phenomenon, as in the last example.
} 
words"), and of language and its relationship to the world ("language is narrower than experience"). By so doing, the reviewer is engaging in a particular kind of relationship with his readers: rather than trying to convince them of the aesthetic qualities of the novel, he is construing a shared system of values with his readers.

Analysis of the occurrence of tokens of Attribution reveals another important dimension of the functionality of interpersonal relations in this text, in particular, and in the corpus, at large:

(...) I take advantage of an idea by José Saramago - his most conspicuous antagonist: "One writes with everything one has inside, only with what one has inside." Lobo Antunes writes with his deafness (which becomes a bunch of voices) and his wounds of war (which add fuel [to his writing]). (paragraph 4 , lines 4 -10)

One more idea by Saramago: "Each one of us can only write his own books. Any book that I write does not take the place of any other book; it it simply occupies its own territory". (...) (paragraph 5, lines 1- 6)

When he is asked what his books are about, Lobo Antunes likes to bring back an idea by writer Francisco Manuel de Melo: "The book is about what is written in it." Words (and words only) generate words. (...)” (paragraph 11, lines 1- 7)

In the examples, Attribution is realized lexicogrammatically as verbal processes in which the Sayer is a well known author (Saramago or Manuel de Melo), which justifies the Verbiage in direct speech, and not in the form of a paraphrase or summary of the authors' ideas ${ }^{6}$. Another important feature of Attribution in the corpus has to do, not just with the kinds of voices that are brought to bear on the text, but also with how they are incorporated into the journalist's text:

I read somewhere that Portuguese writer Antonio Lobo Antunes suffers from hearing problems. His grandfather (from his mother's side), José, was deaf. While still young, his mother, Maria Margarida, also started having hearing problems. (...) (paragraph 1)

Now I remember where I read the story of Lobo Antunes' deafness: in a long interview to Maria Luisa Blanco ("Conversations with Lobo Antunes", Dom Quixote Publisher, Lisboa, 2001) (...) (paragraph 6)

\footnotetext{
${ }^{6}$ The realization of verbiage in direct speech highlights an author's original words or form of expression, with the implication that the Sayer is an authority in a given discourse community.
} 
Unlike quotes in academic texts (or in critical reviews by academics), which require sources to be indicated with a fair degree of accuracy, the first quote gives the reader no information about the source of information: the projecting clause ("I read somewhere") ${ }^{7}$ introduces an adverbial expression with indefinite meaning ("somewhere"). The second quote expands on the first one and gives the reader the accurate source of information, but this is done through a projecting clause codified as a mental process ("now I remember") coupled with an adverbial expression ("now"). These contribute to framing the activity as a non-deliberate course of events.

The offhand way the journalist introduces his sources is not an incidental feature of this particular text, but one that recurs in the corpus, as the next examples suggest:

[While I was] reading, the other day, Anton Tchekhov's correspondence, I ran into a letter, to editor Aleksei Suvórin, which helps [support my ideas]. Says Tchekhov: "I saw everything: the question now is not what I saw, but how I saw [it]". (Texto 11, parágrafo 18)

I know the position I defend is not dominant. Some reject it as illusory, fearful, and submissive. Recently, in a public debate about literature, a lady from the audience (...) asked me if I did not think that my position about literature is "feminine"... (Text 9, paragraph 4)

I have a neighbor who says he is a philosopher. Last week, we met for the purpose of discussing the condominium where we live; as we disagreed on a hydraulics question, and knowing about my passion for literature, he challenged me: "Kant said that reading fiction erodes thinking and destroys memory". And, with an angry face, he went on: "Beware of literature, as it causes great damage". (Text 6, paragraph 1)

In the first example of Attribution, not only the verbal process is codified ("says Tchekhov"), but also the circumstances surrounding the particular choice of Sayer: "I ran into X while I was reading Xy"). The codification of the circumstances provides the background against which the verbal process takes place.

In the second example, the Sayer is realized lexicogrammatically as an indefinite noun phrase ("some reject it") and the verb of saying ("reject")

\footnotetext{
${ }^{7}$ SFL draws a distinction between projected and projecting clauses, the latter understood as the clause which introduces reported speech, and the former a separate clause with the content of what is said.
} 
establishes a relationship between two utterances ("reject" presupposes an earlier utterance). Next, a new verbal process is introduced, with the Sayer identified as a female interlocutor at a public debate about literature. Again, Attribution realizes as a verbal process, with circumstantial information about choice of Sayer.

The third example makes this even clearer, as the Sayer (or journalist's interlocutor) this time is not somebody involved in a discussion of literature, but simply his neighbor. The voices represented in the text are circumstantial voices present in the reviewer's daily routine, both as a journalist who engages in debates about literature, and as an ordinary human being, who attends condominium meetings and is concerned with hydraulics and other down-to-earth matters.

The reviewer is thus seen to inform his view of books with reflections about personal incidents that relate to the experience of reading a novel. Rabinowitz (In: MARSHALL ET ALII, 1995:126) draws a distinction between 'readings of coherence,' in which one is concerned with identifying patterns in a text, and 'readings of configuration', in which one tries to make sense of a text on the basis of their life experiences. This distinction is drawn within the context of discussions of literature in the classroom, and the writer points out that the former (readings of coherence) illustrates the kind of retrospective reading encouraged by teachers, whereas the latter (readings of configuration) is characteristic of students' responses to literature. To many teachers, students must be "socialized into" these readings of coherence, a proposition which implies that readings of configuration are a more "natural" (or naïve) form of response to literature.

There is no denying that responses to literature within an academic or school context are different from those outside an institutional context (as reading done at home, for leisure), or in a different institutional context (as reading literature in the press). However, it is misleading to think about these differences in terms of a contrast between "sophisticated" versus "naïve" reading practices; a more promising line of thinking is one that claims there are competing conceptions of literature in our culture, and of what it means to read literature.

In a recent book entitled Literature at risk, Todorov (2009: 41), demonstrating a willingness to change his earlier positions about the nature of literature, claims that "a very narrow conception of literature, which dissociates it from the world in which it is embedded, prevails in teaching quarters, in [literary] criticism, and even among writers". The 
author further claims that such narrow perception of literature is also commonly held by "journalists who review books". This is not, however, the case with the journalist under consideration, as he draws extensively on his personal experiences to make sense of books being reviewed. Analysis of the corpus also suggests that his response to literature is mostly informed by reflections on the nature of literature and of language, and of the role literature plays in social life.

This translates as a set of specific lexicogrammatical and discursive features in the corpus, which imprint a signature on his texts, and through which he constructs a relationship of proximity with his readers, who are likely to be inclined to engage in readings of configuration, or readings in which they try to make sense of the text, on the basis of their life experiences. This is the kind of reading practice that is, like the journalist's, affected by circumstantial factors.

His readers (who are not necessarily academics or students of literature, though they might be) are more likely to have the same kind of attitude towards literature that Todorov does (2009:23): "Today, if I ask myself why I love literature, the answer which comes spontaneously to my mind is: because it teaches me how to live".

\section{CONCLUSION}

Analysis of the corpus suggests a predominance of appraisal on the dimension of Affect; recurrence of definitional utterances with 'literature', 'language', and 'writing' as referents; practices of Attribution characterized by the following features: 1) reporting not only of voices with high credibility in the relevant discourse community (authors, critics), but also of voices with low credibility (a neighbor, a friend); 2) projecting clauses introducing not only the Sayer but also circumstantial details providing the background against which the verbal process takes place, and whose meaning effect is to highlight the contingencies that surround the act of reading. All these features contribute to giving the journalist's text a particular signature.

José Castello's signature has to be understood against the background of a community of readers who assign "valeur" (MARTIN \& WHITE, 2005: $205)$, or social value, to reading practices informed by personal experience, and by reflections about literature and social life, or about language and the world.

On a theoretical level, this means that the author's signature must be related, through the principle of individuation, to the context of culture which informs his writing (the plurality of competing conceptions of 
literature at this point in time, in our discursive memories), of which the semantic potential of language is a constitutive part (with its distribution of genres and registers, in different discourse domains).

From the perspective of discursive practices in the area of literature, and more specifically within the discursive domain of critical reviews published in the press, the journalist is a cultural agent responsible for construing readers' alignment with a particular conception of literature. Carvalho (2006: 180) argues that most book reviews feature persuasive language, meant to convince readers that a particular book is worth reading, or not. Unlike these reviews, which are ideologically-oriented, or organized on the dimension of truth, Castello's texts are axiologically-oriented, or oriented on the axis of communion (MARTIN \& WHITE, 2005: 211): his book reviews represent an invitation to "communing sympathies".

More than just informative texts, the author's reviews display features of 'bonding, in Stenglin's term: of the "investment of attitude in text" through which shared feelings are construed (STENGLIN 2002 In: MARTIN \& WHITE, 2005: 211). His evaluative signature (the set of specific appraisal resources consistently present in his texts) identifies him for his readers, but also identifies his readers, or aligns them with a particular discourse community: one that shares the view that literature is an overwhelmingly personal experience.

Signature can thus be seen as resulting, not from writers' deliberate and strategic choices of form of expression, but from the kind of interpersonal relationship they have with their readers, in a particular kind of interaction, against the background of the heterogeneous and distinct voices and points of view present in the context of culture. Signature is not an individual's conscious project, but part of a formative semiotic experience, within the discursive regime of one's time and culture.

\section{APPENDIX}

CASTELLO, J. Que estranho viver. Prosa e Verso, Jornal O Globo, 12/ dezembro/2009.

\section{REFERENCES}

BALOCCO, A. E. A construção da identidade no discurso acadêmico: o papel da avaliação no discurso de estudantes de literatura estrangeira. Revista Gragoatá n. 11, p. 177-192, 2001. 
BROOKS, C. \& WARREN, R.P. Understanding poetry. New York: Henry Holt, 1938.

CARVALHO, G. Críticas de livros: um breve estudo da linguagem da avaliação. Linguagem em (Dis)curso, v.6, n. 2, p.179 - 198, 2006.

HASAN, R. Ways of saying: ways of meaning. Selected papers. London: Cassell, 1996.

MAILLOUX, S. Interpretive conventions. Ithaca, N.Y.: Cornell University Press, 1982.

MARSHALL, J.D.; SMAGORINSKY, P.; SMITH, M.W. The language of interpretation: patterns of discourse in discussions of literature. Illinois: NCTE, 1995.

MARTIN, J. M. Tenderness: realisation and instantiation in a Botswanan town. In:

NØRGAARD, N. (ed.). Odense Working Papers in Language and Communication vol. 29, 2008a. p. 30-62.

- - - - - - Innocence: realisation, instantiation and individuation in a Botswanan town. In: KNIGHT, N. \& MAHBOOB, A. (eds.). Questioning linguistics. Cambridge: Cambridge Scholars Publishing, 2008b. p. 2754.

- - - - - \& WHITE, P.R.R. The language of evaluation: appraisal in English. London: Palgrave Macmillan, 2005.

- - - - - Beyond exchange: appraisal systems in English. In: HUNSTON, S. \& THOMPSON, G. (eds.) Evaluation in text: authorial stance and the construction of discourse. Oxford: Oxford University Press, 2000. p.142-175.

THOMPSON, G. Introducing functional grammar. London: Arnold, 1996.

POSSENTI, S. Questões para analistas do discurso. São Paulo: Parábola Editorial, 2009. 
SELDEN, R. A reader's guide to contemporary literary theory. Sussex: Harvester Press, 1988 [ $4^{\text {th }}$ ed.].

TODOROV, T. A literatura em perigo. RJ: DIFEL, 2009. [original French edition 2007] 
